\title{
ANALISIS COMPUTATIONAL FLUID DYNAMIC (CFD) dalam PERANCANGAN TURBIN ARUS LAUT SUMBU VERTIKAL (VERTICAL AXIS OCEAN CURRENT TURBINE, VAOCT)
}

\section{ANALYSIS OF COMPUTATIONAL FLUID DYNAMIC (CFD) ON VERTICAL AXIS OCEAN CURRENT TURBINE (VAOCT) DESIGN}

\author{
R. Bambang Adhitya Nugraha ${ }^{1}$, Nico Prayogo ${ }^{2}$, Muljowidodo Kartidjo ${ }^{2}$ dan Sapto Nugroho ${ }^{2}$ \\ ${ }^{1}$ Pusat Pengkajian dan Perekayasaan Teknologi Kelautan dan Perikanan \\ (P3TKP)-BalitbangKP \\ ${ }^{2}$ Center for Unmanned Studies (CENTRUM)-ITB \\ 1'badhityan@yahoo.com, ${ }^{2}$ prayogo_nico@yahoo.co.id, ssaptoadi@gmail.com
}

Diterima tanggal: 6 Juli 2013, diterima setelah perbaikan: 27 November 2013, disetujui tanggal: 2 Desember 2013

\begin{abstract}
ABSTRAK
Indonesia di masa mendatang akan menghadapi krisis energi konvensional dalam hal kaitannya dengan peningkatan kapasitas kebutuhan, pasokan yang terus menurun, harga tinggi dan permasalahan lingkungan yang ditimbulkan. Potensi energi laut Indonesia yang belum banyak dimanfaatkan dapat menjadi salah satu sumber energi alternatif yang bersih, dapat diandalkan dan terbarukan. Untuk dapat memanen energi yang dihasilkan dari arus laut tersebut, Pusat Pengkajian dan Perekayasaan Teknologi Kelautan dan Perikanan (P3TKP)-BalitbangKP merancang dan mengembangkan twin series vertical turbin tipe drag release yang diharapkan dapat berputar pada putaran rendah. Studi lanjutan tentang bentuk blade-nozzle-guide vane serta kombinasi diantara ketiganya menjadi fokus utama agar dapat menghasilkan target output sebesar $10 \mathrm{~kW}$.
\end{abstract}

Kata kunci: turbin seri kembar, Pembangkit Listrik Tenaga Arus Laut (PLTAL), Computational Fluid Dynamic (CFD), gaya seret dan torsi

\begin{abstract}
In the future, Indonesia will face a crisis of conventional energy with respect to increasing in demands; supply continues to fall, high price and environmental problems posed. Indonesia has huge potential in ocean energy, which can be used as one of the alternative energy source as it is clean, reliable and renewable. To be able to harvest the energy generated from ocean currents, Research and Development Center for Marine and Fisheries Technology (RDCMFT), Agency for Marine and Fisheries Research and Development (AMFRD)designed and developed a twin series vertical type twin drag release that is expected can rotate at low speed. Further study on shape of blade-nozzle guide vane and its vary combination become the main focus in order to produce a target output of $10 \mathrm{~kW}$.
\end{abstract}

Keywords: twin series turbine, Ocean Current Power Plant, Computational Fluid Dynamic (CFD), drag force and torque

\section{PENDAHULUAN}

Salah satu dukungan Kementerian Kelautan dan Perikanan untuk program diversifikasi sumber energi terbarukan sebagai salah jawaban untuk permasalahan krisis energi nasional saat ini adalah meningkatkan eksplorasi sumber daya energi berbasis arus (tidal current), pasang surut (tidal range), gelombang(wave) dan perbedaan suhu air laut (ocean thermal) serta pengembangan teknologi konversinya.Dari keempat energi laut tersebut, studi potensi dan pengembangan teknologi nasional konversi energi yang berasal dari arus pasang surut dan gelombang telah mengalami perkembangan cukup pesat meski sebagian besar masih dalam tahapan penelitian dan ujicoba skala laboratorium atau lapangan terkondisi (Erwandi et al., 2011; Hantoro et al., 2011). 
Energi yang berasal dari arus laut pada saat ini dianggap sangat menjanjikan karena sifatnya yang dapat diprediksi dan terjadi secara periodik. Teknologi ekstraksi energi arus laut memiliki prinsip kerja yang sama dengan teknologi energi angin yaitu dengan mengubah energi kinetik fluida (angin atau arus air) menjadi energi rotasi melalui bilah (blade) turbin untuk menghasilkan energi listrik. Daya yang dihasilkan oleh arus laut lebih besar dibandingkan dengan daya yang dihasilkan oleh turbin angin karena massa jenis air laut (1025 $\mathrm{kg} / \mathrm{m}^{3}$ ) lebih besar dari pada massa jenis udara $\left(1.223 \mathrm{~kg} / \mathrm{m}^{3}\right)$. Jika pergerakan air laut diekstraksi menjadi energi listrik pada suatu turbin, maka dibutuhkan kecepatan arus yang jauh lebih kecil dibandingkan kecepatan gerak aliran udara yang dibutuhkan untuk menghasilkan daya listrik yang sama. Dengan mempertimbangkan hal tersebut disimpulkan bahwa energi keinetik arus laut merupakan sumber energi terbarukan yang potensial di Indonesia.

Sejak tahun 2010, Pusat Pengkajian dan Perekayasaan Teknologi Kelautan (P3TKP), Balitbang KP mencoba mengembangkan model dan prototipe Pembangkit Listrik Tenaga Arus Laut (PLTAL) Putaran Rendah (Low Velocity Blade Release Turbine) tipe seret lepas (drag release). Hasil ujicoba skala laboratorium dan lapangan menunjukkan bahwa meski belum mencapai target output daya yang diharapkan (5 $\mathrm{kW}$ ), turbin tipe tersebut memiliki nilai efisiensi daya turbin yang melebihi $50 \%$ serta memiliki torsi dan TSR yang besar yang memungkinkan bilah mulai berputar (cut in speed) pada kecepatan rendah (Nugroho, 2011).

Tujuan dari penelitian ini adalah untuk menentukan bentuk blade, nozzle dan guide vane yang tepat untuk menghasilkan besaran torsi, gaya seret dan daya yang diharapkan dengan melakukan simulasi Computational Fluid Dynamic (CFD) untuk setiap komponen turbin tersebut dan kombinasi antar komponen tersebut. Turbin yang dikembangkan merupakan twin turbine yang merupakan gabungan series dari dua single turbine tipe drag release dengan putaran yang berbeda satu dengan lainnya (counter rotations). Tipe Twin turbine tersebut sangat cocok untuk lingkungan laut yang memiliki arus/arus pasut yang tidak terlalu besar (Hiraki et al., 2012).

\section{BAHAN DAN METODE}

Salah satu faktor yang berpengaruh terhadap gaya angkat (lift) dan gaya gesek (drag) sebuah turbin adalah bentuk geometri bilah turbin yang merupakan komponen utama untuk menangkap arus laut untuk kemudian dikonversikan menjadi gerakan mekanik.

Turbin arus laut memiliki geometri yang kompleks dengan adanya profil potongan, panjang rusuk dan sudut pitch yang bervariasi. Sampai saat ini proses desain turbin arus laut masih mengandalkan teknik eksperimen dan metoda numerik untuk analisis. Faktor-faktor ini melatarbelakangi penggunaan CFD sebagai metoda desain dan analisis. CFD dimanfaatkan tidak hanya untuk mengidentifikasi karakteristik hidrodinamik arus laut yang melewati suatu turbin, namun juga untuk menentukan besaran gaya seret dan angkat (drag and lift force) serta torsi (torque) mekanik teoritik yang dihasilkan dari energi kinetik arus laut.

Parameter utama yang akan menentukan sistem turbin yang dirancang adalah gaya drag dan torsi poros turbin yang akan mewakili besar daya hidrolik yang dihasilkan, Pada simulasi CFD ini bagian-bagian utama turbine seperti blade, nozzle dan guide vane akan dianalisis dan dioptimasi secara terpisah untuk melihat performanya masingmasing dan hasil optimasinya akan dimanfaatkan untuk analisis kombinasi bilah-nozzle-guide vane turbin secara keseluruhan.

Bentuk bilah turbin dan nozzle akan dibuat dalam 3 bentuk geometri yang berbeda untuk kemudian masing-masing dipilih berdasarkan output daya yang paling tinggi. Guide vane berfungsi untuk mempercepat arus yang masuk ke dalam area bilah sehingga diharapkan dapat meningkatkan efisiensi yang dihasilkan.

Tahap-tahap analisis CFD yang dilakukan adalah sebagai berikut:

1. Pembuatan geometri ketiga komponen turbin tersebut menggunakan software CAD (computer aided design) atau Gambit. Proses awal dari pekerjaan ini adalah pembuatan geometri dengan mempergunakan perangkat lunak Gambit yang terintegrasi dengan Fluent (software CAD Solidworks 2011). Hasil modeling 3D pada Solidworks kemudian diexport ke dalam bentuk ACIS (*.sat) untuk 
kemudian dibaca pada Gambit;

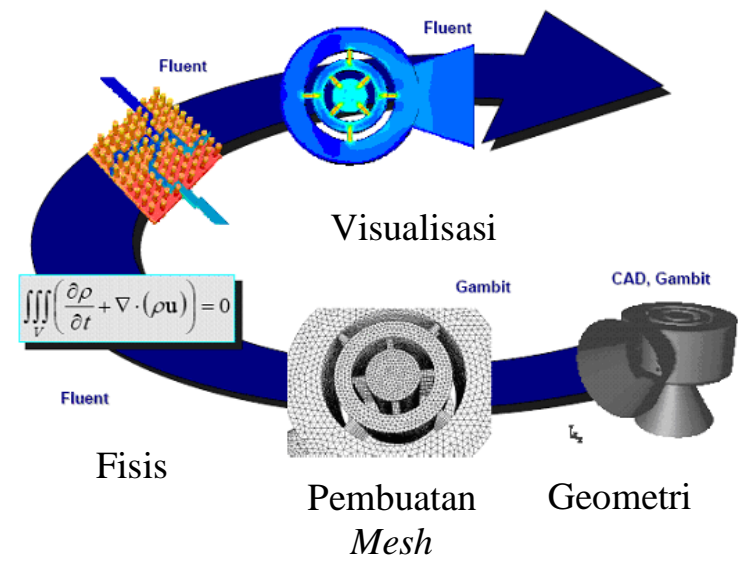

Gambar 1. Aliran proses dalam analisis Computational Fluid Dynamics

Figure 1. Flowchart process for CFD analysis

2. Pembuatan mesh pada geometri yang telah dibuat, yaitu dengan membaginya menjadi elemen volume hingga. Hal ini dilakukan pada software Gambit;

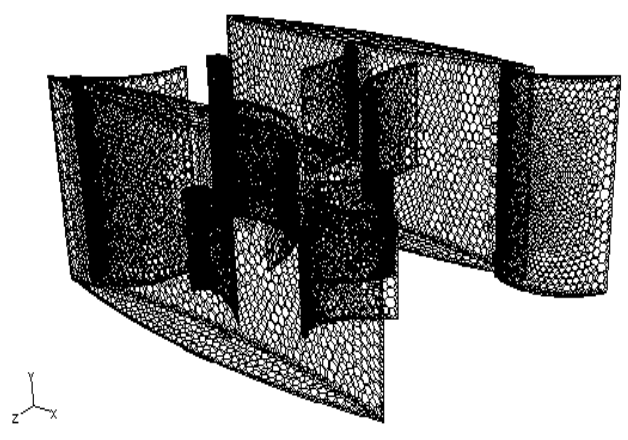

Gambar 2. Proses meshing pada Gambit Figure 2. Meshing process on Gambit

3. Analisis fisis, matematik dan tampilan pada Fluent;

4. Penerapan kondisi batas untuk kemudian dimanfaatkan lebih lanjut pada Fluent. Proses ini meliputi penentuan lokasi dan jenis batasan (boundaries) serta penentuan informasi parameter dari batasan tersebut. Pada Gambit, pendefinisian kondisi batas hanya terbatas pada lokasi dan jenis kondisi batas. Pemberian nilai parameter dilakukan lebih lanjut pada Fluent.

Kondisi perairan diasumsikan memiliki kecepatan rata-rata sebesar $1.2 \mathrm{~m} / \mathrm{s}$ dan bilah turbin akan mulai bergerak (cut in speed) pada kecepatan minimum $0.88 \mathrm{~m} / \mathrm{s}$.

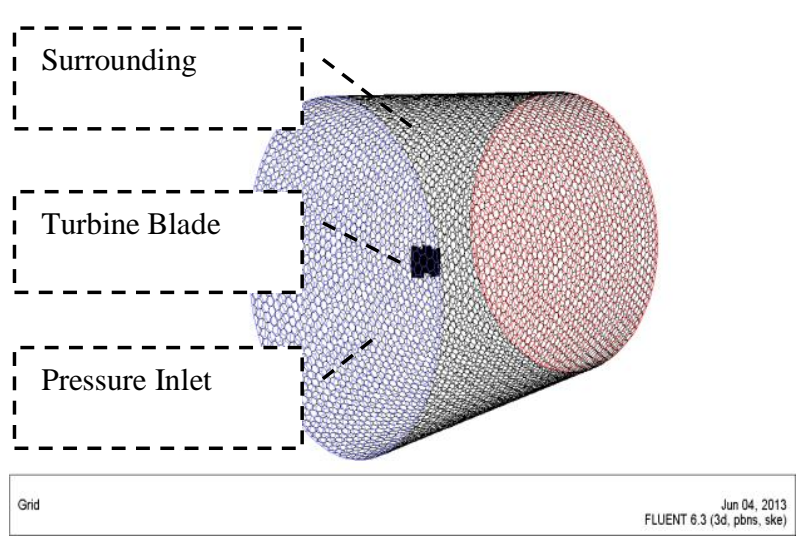

Gambar 3. Grid polyhedral dan kondisi batas untuk simulasi CFD airfoil blade turbine

Figure 3. Polyhedral grid and boundary for CFD simulation of airfoil blade turbine

Turbin arus laut disimulasikan pada CFD seakanakan berada pada terowongan air dengan memberikan kecepatan masuk pada air dan turbin pada kondisi diam. Parameter analisis yang akan diperbandingkan adalah parameter torsi dan gaya hambat air/drag force.

\section{HASIL DAN PEMBAHASAN}

Sebelum melakukan simulasi konstruksi kembar, terlebih dahulu ditampilkan hasil CFD pada single turbin untuk melihat pola aliran arus jika memasukin inlet turbin serta seberapa besar torsi, gaya drag dan power yang dihasilkan.

\subsection{Perbandingan Airfoil Bilah Turbin}

Untuk jenis bilah yang akan diaplikasikan pada turbin arus laut, proses analisis dilakukan pada tiga jenis penampang airfoil seperti terlihat pada Gambar 5.

Hasil analisis CFD dapat dilihat bahwa daya terbesar dihasilkan oleh airfoil tipe 2, di mana konfigurasi ini dapat menghasilkan daya sebesar 3126,6 Watt. Pada konfigurasi 1 dan 3 daya yang dihasilkan sebesar 2504 watt dan 2724 watt (Tabel $1)$.

Gaya seret sistem terendah juga diperoleh dari konfigurasi airfoil 2 dengan besar $4849 \mathrm{~N}$ atau sekitar 485 kgf. Dari ketiga konfigurasi dasar yang dilakukan analisis belum ada yang dapat memenuhi target daya per unit turbin sebesar $5 \mathrm{~kW}$ pada kecepatan arus $1,2 \mathrm{~m} / \mathrm{s}$. 


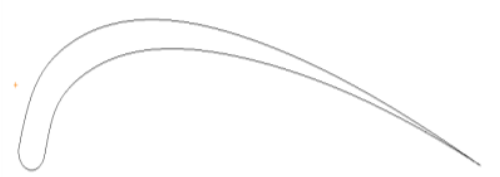

Airfoil Bilah 1

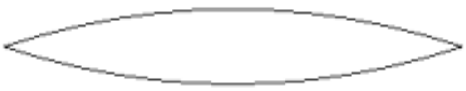

Airfoil Bilah 2

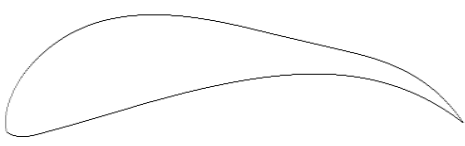

Airfoil Bilah 3

Gambar 4. Tipe airfoil blade turbine Figure 4. Types of airfoil bladeturbine

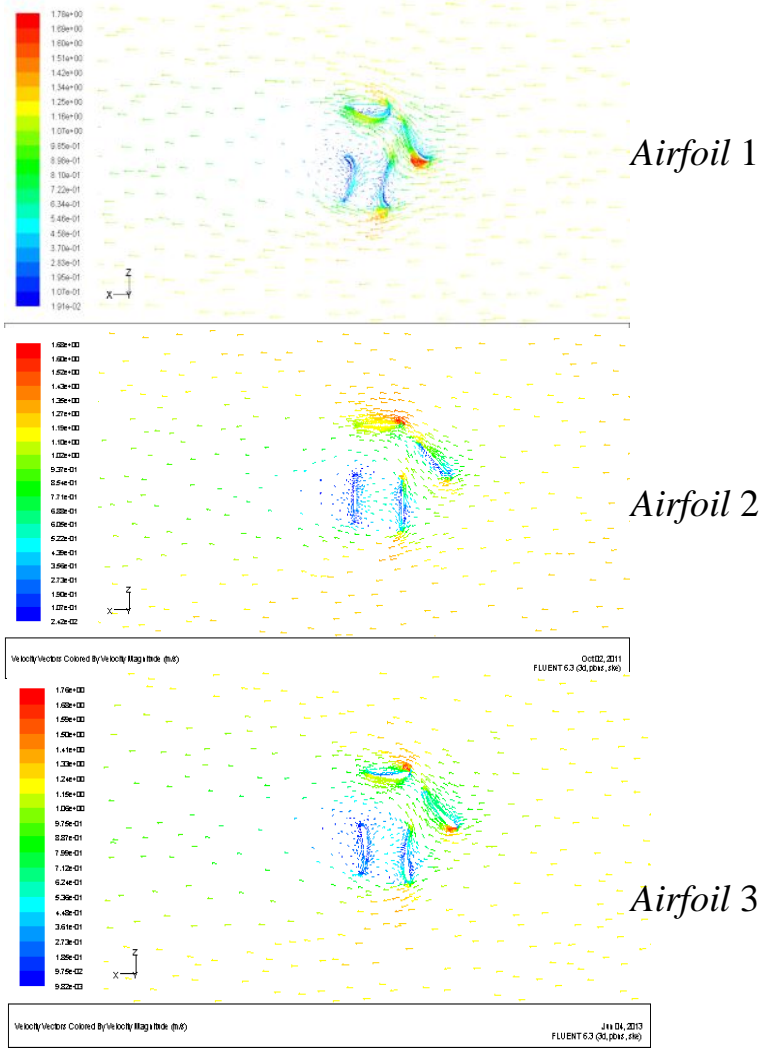

Gambar 5. Kontur hidrodinamika arus laut pada airfoil tipe 3

Figure 5. Hydrodynamic contour of ocean current on the three types of airfoil
Tabel 1. Perbandingan hasil simulasi pada ketiga bilah Table 1. Comparison of simulation result on 3 types of blades

\begin{tabular}{cccc}
\hline Airfoil & $\begin{array}{c}\text { Drag } \\
\text { Force (N) }\end{array}$ & $\begin{array}{c}\text { Torque } \\
\text { (Nm) }\end{array}$ & $\begin{array}{c}\text { Power } \\
\text { (Watt) }\end{array}$ \\
\hline Type 1 & 5738.9 & 2845.5 & 2504.04 \\
\hline Type 2 & 4849.36 & 3552.98 & 3126.6 \\
\hline Type 3 & 5394,12 & 3096,25 & 2724.7 \\
\hline
\end{tabular}

\subsection{Perbandingan Airfoil Nozzle}

Tiga jenis penampang airfoil nozzle seperti terlihat pada Gambar 7.

Airfoil Nozzle 1

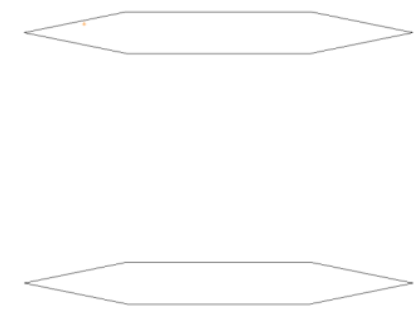

Airfoil Nozzle 2 
Pada analisis ini parameter yang dibandingkan adalah kenaikan kecepatan air yang diberikan oleh nozzle dan besaran gaya hambat air yang diberikan oleh nozzle. Dari hasil perbandingan ketiga buah konfigurasi nozzle diperoleh kesimpulan bahwa, perkalian kecepatan fluida terbesar didapat dari penerapan konfigurasi 2 dimana diperoleh kecepatan 1,251 kali lebih besar dibanding dengan kecepatan masuk fluida sekitar. Namun hal ini dikompensasi dengan besar gaya drag yang dihasilkan yang juga lebih besar, sebesar 611,38 N (Tabel 2).

Nozzle tipe 3 yang merupakan setengah potongan nozzle tipe 1 menunjukkan bahwa kenaikan kecepatan tidak terpengaruh oleh penghilangan airfoil bagian luar, namun mampu mereduksi gaya hambat air secara signifikan. Terjadi pengurangan gaya drag sebesar $100 \mathrm{~N}$.

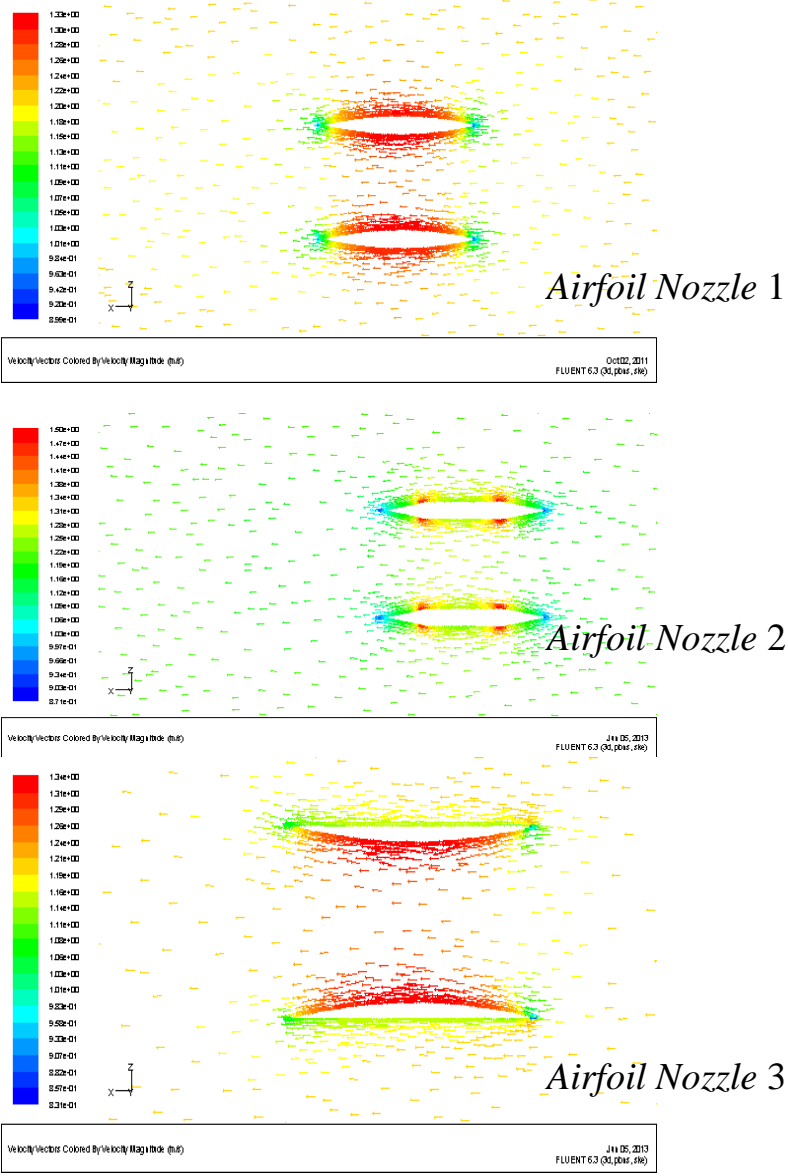

Gambar 7. Kontur hidrodinamika arus laut pada airfoil tipe 3

Figure 7. Hydrodynamic contour of ocean current on the three types of airfoil
Tabel 2. Perbandingan hasil simulasi pada ketiga airfoil nozzle

Table 2. Comparison of simulation on types of airfoil nozzle

\begin{tabular}{cccc}
\hline Airfoil & $\begin{array}{c}\text { Drag } \\
\text { Force (N) }\end{array}$ & $\begin{array}{c}\text { Torque } \\
(\mathbf{N m})\end{array}$ & $\begin{array}{c}\text { Power } \\
\text { (Watt) }\end{array}$ \\
\hline Type 1 & 460.6 & 1.104 & 460.6 \\
\hline Type 2 & 611.38 & 1.251 & 611.38 \\
\hline Type 3 & 362.18 & 1.114 & 362.18 \\
\hline
\end{tabular}

\subsection{Penambahan Guide vane}

Pada analisis ini diperlihatkan pengaruh penambahan sudu pengarah pada bagian depan dan belakang nozzle turbin arus laut. Guide vane sangat efektif untuk mengarahkan arus laut agar lebih banyak melewati bilah turbin sehingga energi yang dihasilkan menjadi lebih besar (Hiraki et.al., 2013). Parameter utama yang diamati adalah perubahan karakteristiknya adalah pada parameter kecepatan fluida masuk dan gaya hambat fluida pada sistem. Tipe guide vane yang digunakan adalah tipe drag release yang dapat menyesuaikan dengan karakteristik aliran pasang surut yang bekerja maju mundur.

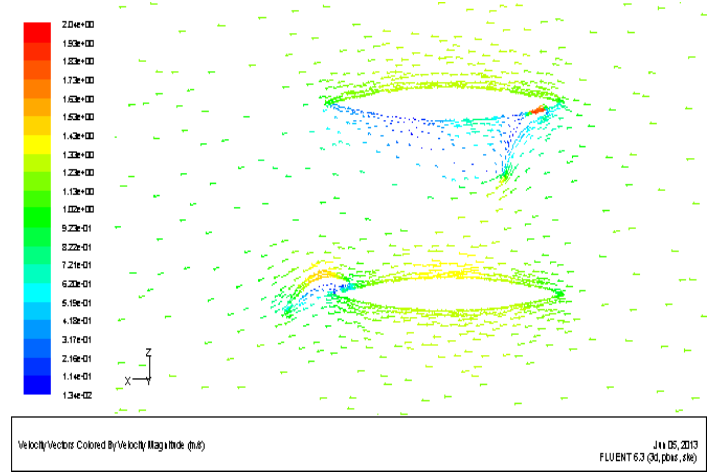

Gambar 8. Kontur hidrodinamika arus laut untuk penambahan guide vane

Figure 8. Hydrodynamic contour of ocean current due to additional guide vane on nozzle

Dari hasil analisis diperoleh kesimpulan bahwa penambahan sudu pengarah dapat meningkatkan perkalian kecepatan fluida sebesar 1,69. Namun gaya hambat air juga ikut meningkat secara signifikan menjadi 10 kali lebih besar dibandingkan konfigurasi nozzle tanpa guide vane. Namun konfigurasi ini memiliki keuntungan lain berupa lebih terarahnya aliran fluida masuk ke daerah blade yang aktif menyumbang torsi positif, 
dan mengurangi sumbangan torsi negatif dari blade di kondisi release.

\subsection{Kombinasi Blade-Nozzle-Guide Vane}

Berdasarkan pada hasil analisis komponen individual turbin arus laut, kemudian akan dilakukan analisis lebih lanjut mengenai efek kombinasi antar komponen yang secara terpisah telah memiliki nilai-nilai torsi, gaya gesek dan daya yang terbaik untuk menjadi sebuah konfigurasi utuh turbin. Analisis yang dilakukan berupa kombinasi airfoil blade type 2, nozzle type 1 dan guide vane.
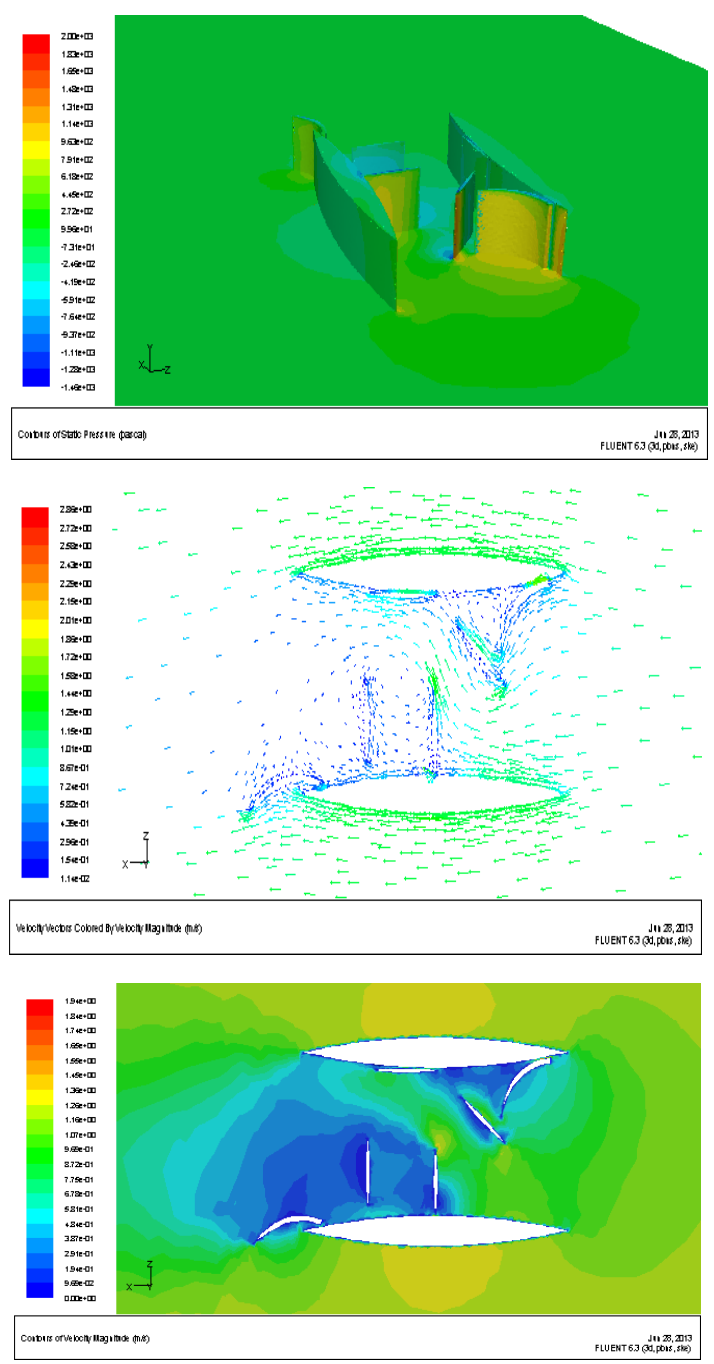

Gambar 9. Kontur hidrodinamika arus laut untuk kombinasi bilah 2, nozzle 1 dan guide vane

Figure 9. Hydrodynamic contour of ocean current on the combination of Blade 2, nozzle 1 and guide vane
Tabel 3. Nilai torsi, gaya seret dan daya yang dihasilkan dari kombinasi bilah 2, nozzle 1 dan guide vane

Table 3. Torque, drag force and power generated from the combination of blade 2, nozzle 1 and guide vane

\begin{tabular}{|c|c|c|c|}
\hline $\begin{array}{c}\text { Airfoil } \\
\text { Type }\end{array}$ & $\begin{array}{c}\text { Drag } \\
\text { Force (N) }\end{array}$ & $\begin{array}{c}\text { Torque } \\
\text { (Nm) }\end{array}$ & $\begin{array}{c}\text { Power } \\
\text { (Watt) }\end{array}$ \\
\hline Bilah 2 & 7037.02 & 3065.8 & 4559.46 \\
\hline
\end{tabular}

Tabel 3 memperlihatkan perbandingan gabungan blade, nozzle dan guide vane. Konstruksi turbin menggunakan airfoil blade 2 memberikan hasil yang paling mendekati target keluaran yang diinginkan untuk single turbine yaitu sebesar $5 \mathrm{~kW}$, daya maksimum yang diperoleh adalah 4559.46 watt. Hasil ini didapat pada sudut putaran turbin 0 derajat.

Untuk meningkatkan daya yang dihasilkan maka dilakukan modifikasi sudut guide vane pada beberapa sudut yang berbeda dan dilihat besaran torsi daya yang dihasilkan (Tabel 4).

Tabel 4. Nilai torsi dan daya yang dihasilkan dari kombinasi bilah 2, nozzle 1 dan guide vane dengan sudut yang berbeda.

Table 4. Torque and power generated from the combination of blade 2, nozzle guide vane 1 and with different angle

\begin{tabular}{|c|r|r|c|}
\hline $\begin{array}{c}\text { Airfoil } \\
\text { Type }\end{array}$ & $\begin{array}{c}\text { Drag } \\
\text { Force (N) }\end{array}$ & $\begin{array}{c}\text { Torque } \\
\text { (Nm) }\end{array}$ & $\begin{array}{c}\text { Power } \\
\text { (Watt) }\end{array}$ \\
\hline Airfoil 2 & $0 \mathrm{deg}$ & 3065.80 & 4559.458 \\
\hline & $+7.5 \mathrm{deg}$ & 2982.07 & 4434.935 \\
\hline & $+15 \mathrm{deg}$ & 311.86 & 4636.881 \\
\hline
\end{tabular}

Tabel di atas memperlihatkan konfigurasi optimum gabungan blade, nozzle dan guide vane adalah pada konfigurasi airfoil 2 dengan sudut guide vane ditingkatkan sekitar 15 derajat. Kondisi ini menghasilkan daya keluaran sebesar 4636,881 watt. Analisis berikutnya dilakukan untuk mengoptimasi konfigurasi blade airfoil 2 pada kondisi twin turbine.

\subsection{Konfigurasi Twin Turbine}

Pada analisis berikutnya akan dilakukan simulasi numerik fluida pada kondisi twin turbine, yang dilakukan pada dua kecepatan aliran masuk yaitu $1,2 \mathrm{~m} / \mathrm{s}$ dan $2 \mathrm{~m} / \mathrm{s}$. Kedua sistem bilah turbin tersebut akan berputar dengan arah yang berbeda satu dengan yang lainnya yang berguna untuk meningkatkan output daya yang dihasilkan Hiraki et al. (2012) melakukan model double stage twin- 
turbine dengan arah rotasi kedua turbin tersebut berlawanan arah. Putaran kedua rotor tersebut akan mempercepat putaran generator sehingga menghasilkan daya listrik yang lebih besar.

Hasil simulasi twin-turbine tersebut kemudian diperbandingkan untuk melihat kondisi operasi optimum bagi turbin arus laut dalam mencapai rated power output sebesar $2 \times 5 \mathrm{~kW}$.

a. Kecepatan arus $1.2 \mathrm{~m} / \mathrm{s}$

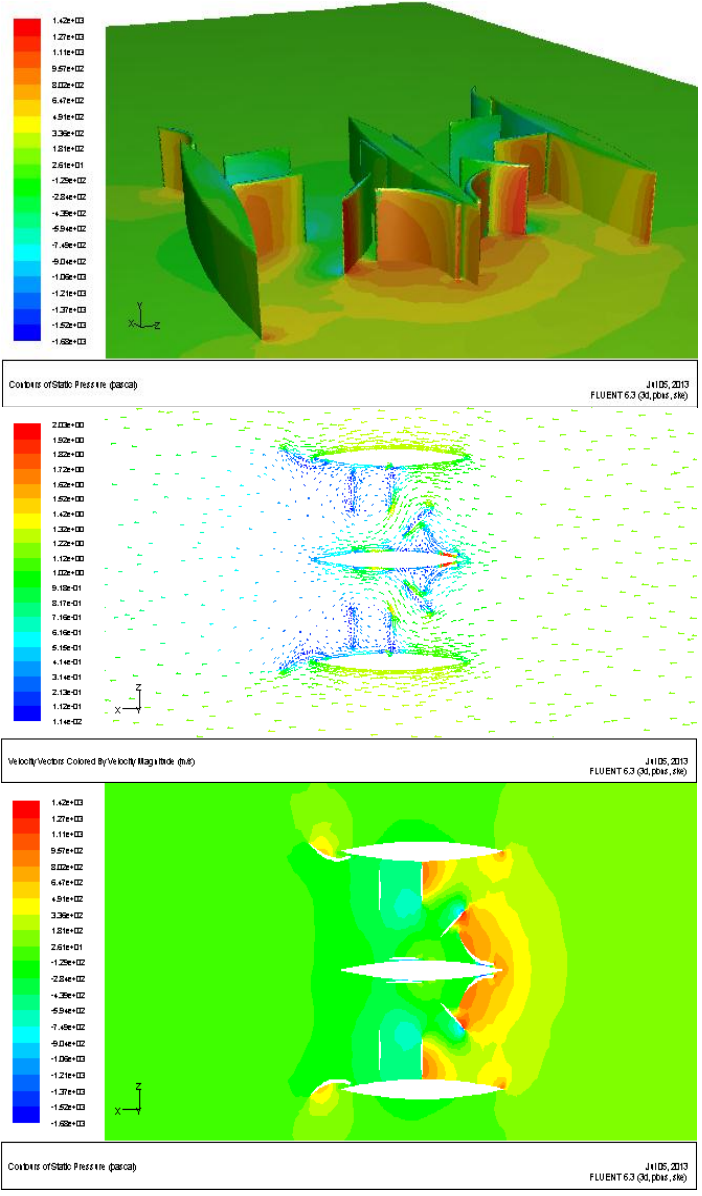

Gambar 10. Kontur hidrodinamika arus laut untuk kombinasi bilah 2, nozzle 1 dan guide vane pada kecepatan $1.2 \mathrm{~m} / \mathrm{s}$

Figure 10. Hydrodynamic contour of ocean current on the combination of blade 2, nozzle 1 and guide vane at speed $1.2 \mathrm{~m} / \mathrm{s}$

- Total drag force $=14361.374 \mathrm{~N}$

- Turbine blade's torque at $1.2 \mathrm{~m} / \mathrm{s}=2 \times 3498.58$ $\mathrm{N} \mathrm{Nm}$

- Hydraulic power $=2 \times(1.69 \times 3498.58 \mathrm{Nm} \times$ $0.88 \mathrm{rad} / \mathrm{s})=2 \times 5203.5 \mathrm{watt}$
- Outputpower $=$ hydraulic power $\mathrm{x}$ system efficiency $=2 \times 5203.5 \times 50 \%=2 \times 2,601.75$ watt.

b. Kecepatan arus $2 \mathrm{~m} / \mathrm{s}$
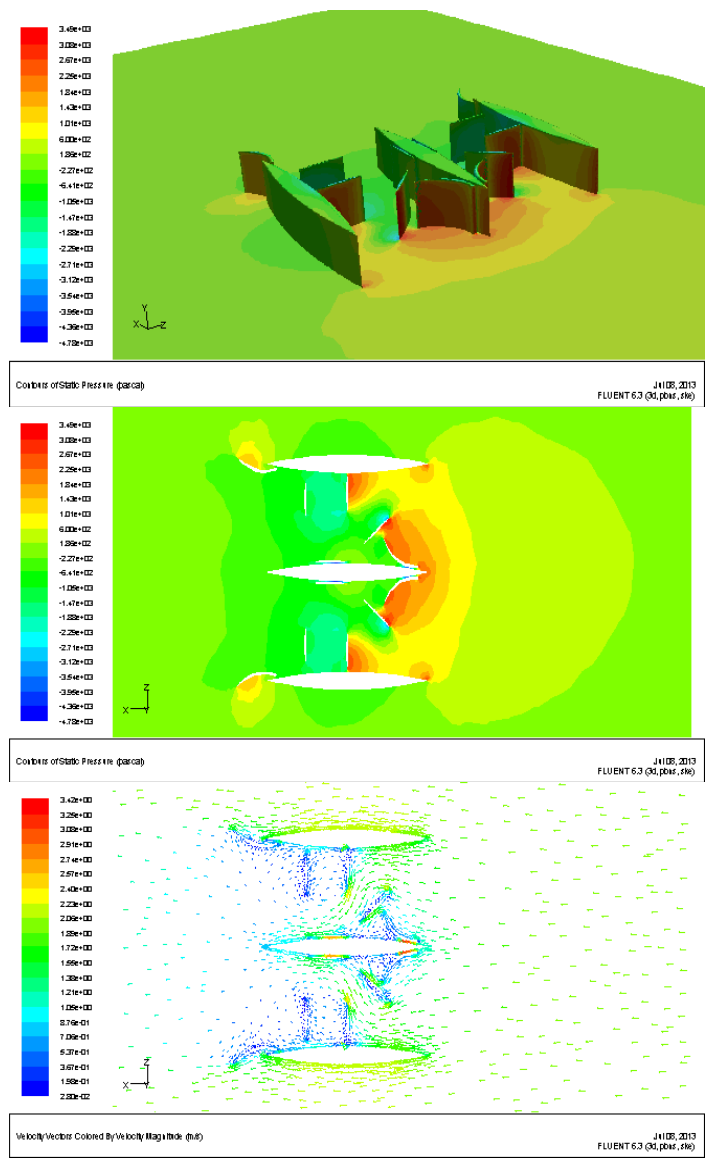

Gambar 11. Kontur hidrodinamika arus laut untuk kombinasi bilah 2, nozzle 1 dan guide vane pada kecepatan $2 \mathrm{~m} / \mathrm{s}$

Figure 11. Hydrodynamic contour of ocean current on the combination of blade 2, nozzle 1 and guide vane at speed $2 \mathrm{~m} / \mathrm{s}$

- Total drag force $=39209.15 \mathrm{~N}$

- Turbine blade's torque at $1.2 \mathrm{~m} / \mathrm{s}=2 \times 3498.58$ $\mathrm{N} \mathrm{Nm}$

- Hydraulic power $=2 \times(1.69 \times 10154.369 \mathrm{Nm} \times$ $0.88 \mathrm{rad} / \mathrm{s})=2 \times 15,101.56$ watt

- Output power $=$ hydraulic power $\mathrm{x}$ system efficiency $=2 \times 15,101.56 \times 50 \%=2 \times 7,550.7$ watt. 


\section{KESIMPULAN DAN SARAN}

Dalam penelitian VAOCT ini telah dilakukan analisis simulasi numerik dengan CFD pada beberapa tipe airfoil, nozzle dan guide vane untuk mendapatkan target output daya yang optimal.

Hasil keluaran daya maksimum diperoleh melalui konfigurasi airfoil blade 2, airfoil nozzle 1 dan guide vane 1. Penggunaan nozzle tipe 1 untuk konfigurasi saluran masuk turbin memberikan penambahan daya keluaran sebesar $10 \%$ sedangkan penggunaan sudu pengarah memberikan tambahan daya sebesar 53\%. Selain itu telah dilakukan pula konfigurasi dua tingkat untuk konstruksi bilah yang bertujuan untuk menggurangi fluktuasi daya output (agar luaran daya stabil). Prediksi daya keluaran turbin: Dengan menggunakan asumsi efisiensi mekanik $70 \%$, dan efisiensi elektrik $70 \%$, diperoleh prediksi daya keluaran turbin sebesarm 2 x 2,601.75 watt pada kecepatan masuk fluida $1,2 \mathrm{~m} / \mathrm{s}$ dan $2 \times 7,550.7$ watt pada kecepatan masuk fluida $2 \mathrm{~m} / \mathrm{s}$.

\section{DAFTAR PUSTAKA}

Erwandi, Afian, K., Sasoko, P., Rina, Wijanarko, B., Marta, E., \& Rahuna, D. (2011). Vertical axis marine current turbine development in Indonesian Hydrodynamic LaboratorySurabaya for tidal power plant. Paper presented at International Conference and Exhibition on Sustainable Energy and Advanced Materials (ICE SEAM 2011). Retrieved from http://iceseam.com/downloads/doc_download/ 11-15-23vertical-axis-marine-current-turbinedevelopment-in-indonesian-hydrodynamiclaboratory-.html

Hantoro, R., Utama, I.K.A.P., Sulisetyono, A., \& Erwandi. (2011). Lateral force fluctuation on the shaft of vertical-axis ocean current turbine. Australian Journal of Basic and Applied Science, 5(7): 121-128. Retrieved from

http://ajbasweb.com/old/ajbas/2011/July2011/121-128.pdf

Hiraki, K., Nishida, K., Wakita, R., Takao, M., \& Watanabe, T. (2013). Guide vanes for darrieus water turbine in tidal current. Paper presented at International Conference on Renewable Energies and Power Quality
(ICREPQ'13), Spain. Retrieved from http://www.icrepq.com/icrepq'13/567hiraki.pdf.

Hiraki, K., Wakita, R. \& Kanemeoto, T. (2012). Demonstrative power generation by twinrunner darrieus turbine in Kanmon Strait. Proceedings of the Twenty-Second (2012) International Offshore and Polar Engineering Conference Rhodes, Greece. Retrieved from http://e-

book.lib.sjtu.edu.cn/isope2012/data/papers/vol 1/2012-SN-01Hiraki.pdf.

Hiraki, K., Wakita, R., Takao, M. \& Yagami, R.. (2012). Characteristics of twin-runner darreus wtaer-turbine for tidal current power generation. Paper presented at International Conference on Renewable Energies and Power Quality (ICREPQ'12).

Nugroho, D. (2011). Bilah lengkung seret lepas untuk peningkatan efisiensi pada turbin arus laut sumbu vertikal. 